\title{
Now is the Time
}

Founded in 1991, TESCAN is becoming an industry leader by designing quality products, creating innovative solutions, and listening to our customers' needs.

- Thermionic Scanning Electron Microscopes

- Field Emission Scanning Electron Microscopes

- FIB-SEM Workstations

- Raman Correlative Microscopy

- Mineral Analysis Solutions

-ToF-SIMS

\section{Quality. Reliability. Performance.}

\section{www.tescan-usa.com}




\section{Visit Often for Updates!}

\section{http://microscopy.org/MandM/2014}

Call for Papers

Paper Submission Open: November 15, 2013

Program Details

Hartford Area \& Hotel Information

Hotel reservations available

January 2014
Paper Submission Portal

Paper Submission Deadline: February 8, 2014

\section{Awards Information}

Online Registration

Opens February 2014

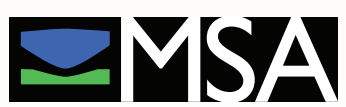

Microscopy Society of America
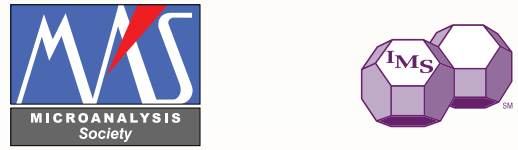

International

Metallographic

Society

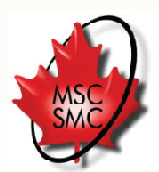

IUMAS 


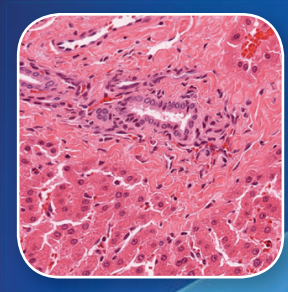

Pelco BioWave Pro

Fast, Low Temperature

Microwave Tissue Processing

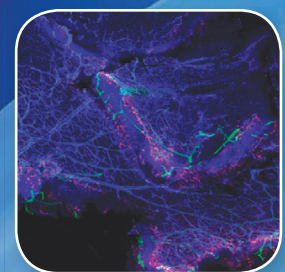

- Rapid specimen turnaround

- Low temperature environment

- Programmable processing

- Consistent quality results

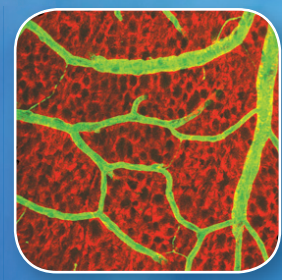

Application kits for paraffin processing, decalcification, confocal, light and electron microscopy available.

\section{D TED PELLA, INC.}

Microscopy Products for Science and Industry

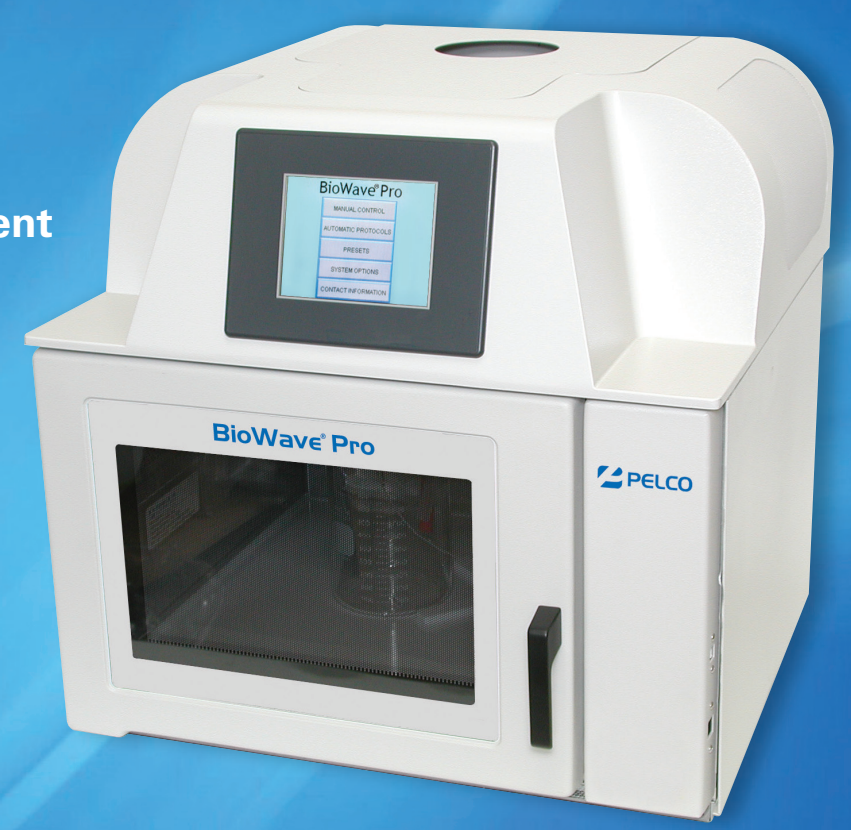

www.tedpella.com sales@tedpella.com 800.237.3526

\section{A 2 Aberration Corrected Scanning - M Transmission Electron Microscopy}

\section{next generation of imaging tools capable of providing information at the Angstrom scale}

The improvement in resolution and sensitivity that AC-STEM provides is universally applicable for investigations of nanometer scale materials.

We specialize in studies involving:

- ultrathin films

- nanoparticles

- complex interfaces

- multiphase materials

- interlayer mixing

- grain boundary engineering
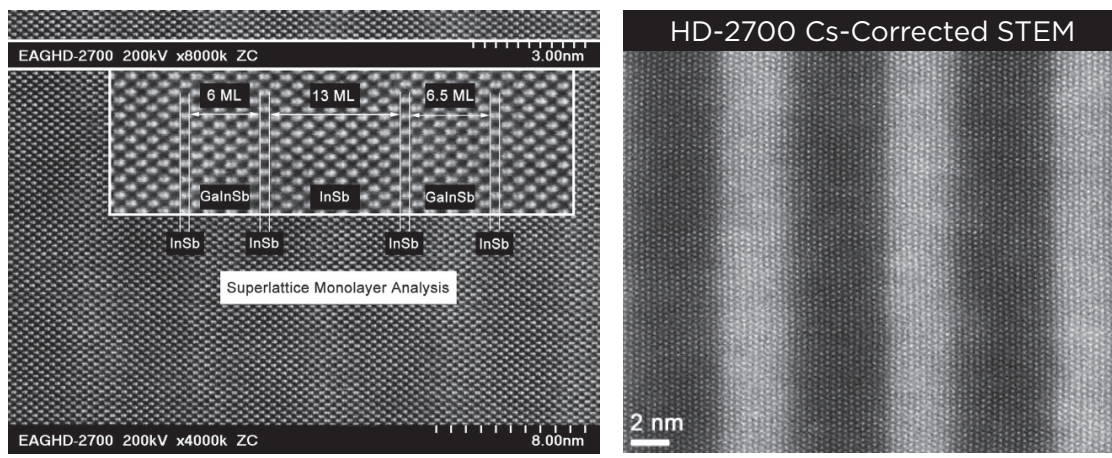

- surface phenomena

We look forward to tackling your toughest materials problems! Contact us today at microscopy@eag.com to learn more about our full suite of Materials Characterization techniques. Other microscopy tools available: SEM, EDS, Dual Beam, EBSD, EELS and more...

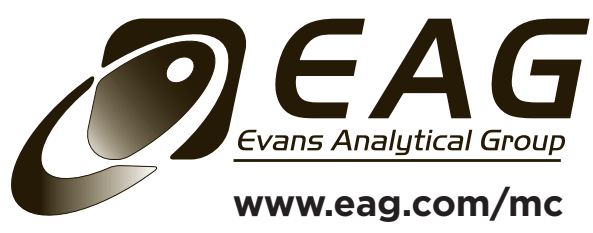




\section{Save the Date!}

\section{AUGUST 3-7, 2014 • M\&M 2014 \& IUMAS-6}

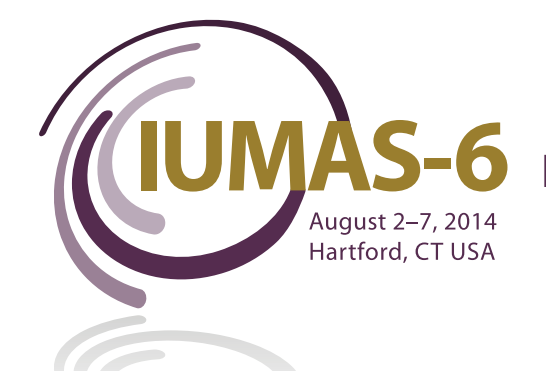

held in conjunction with

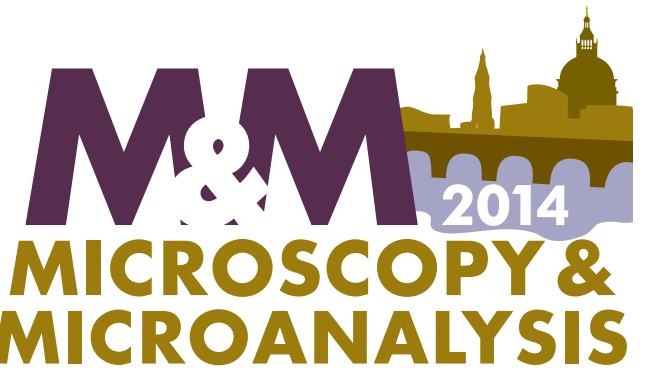

AUGUST 3-7•HARTFORD, CT

\section{Expand your Knowledge of Microscopy with}

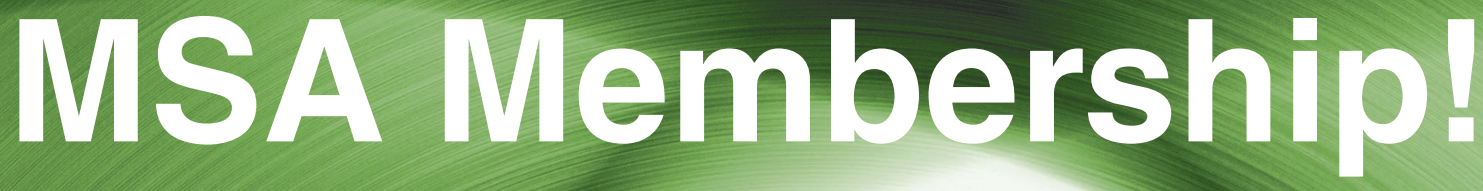

Whether your primary focus is in optical, electron or scanning probe microscopy, the biological or the physical sciences, MSA takes your knowledge to the next level!

Members Receive:

-A personal subscription to MSA's official journal, Microscopy and Microanalysis, and MSA's popular bi-monthly magazine, Microscopy Today.

- Peer Networking through the Society's Focused Interest Groups and Local Affiliated Societies.
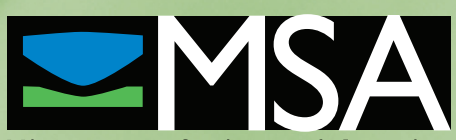

Microscopy Society of America
- Plus discounts on books, journals and other educational materials.

- MSA Awards Programs, Scholarships, Speaker Opportunities, and much more! 


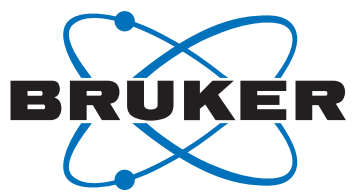

\section{5-in-1 fantasy: Giralope.}
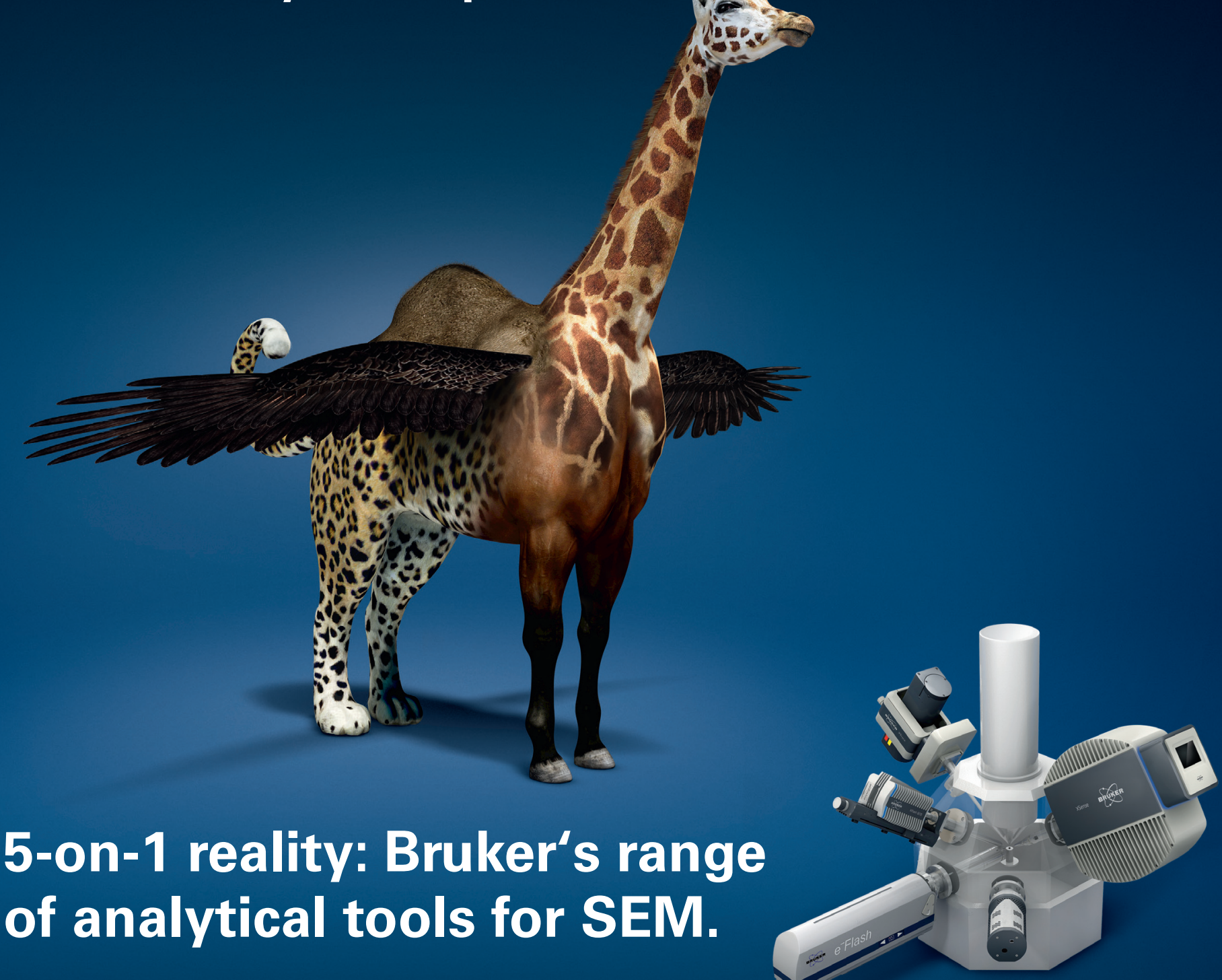

EDS, EBSD, WDS, Micro-XRF and Micro-CT - Bruker is the world's only manufacturer to offer five analysis methods for SEM. Plus, our new ESPRIT 2.0 software not only controls our QUANTAX EDS and QUANTAX CrystAlign EBSD but also, via its functional interface, our innovative new XSense WD spectrometer and XTrace micro-spot X-ray source. And because we know what you expect of us, we are already thinking about our next innovation. Someone has to be first.

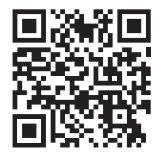

www.bruker-5on1.com

Innovation with Integrity 

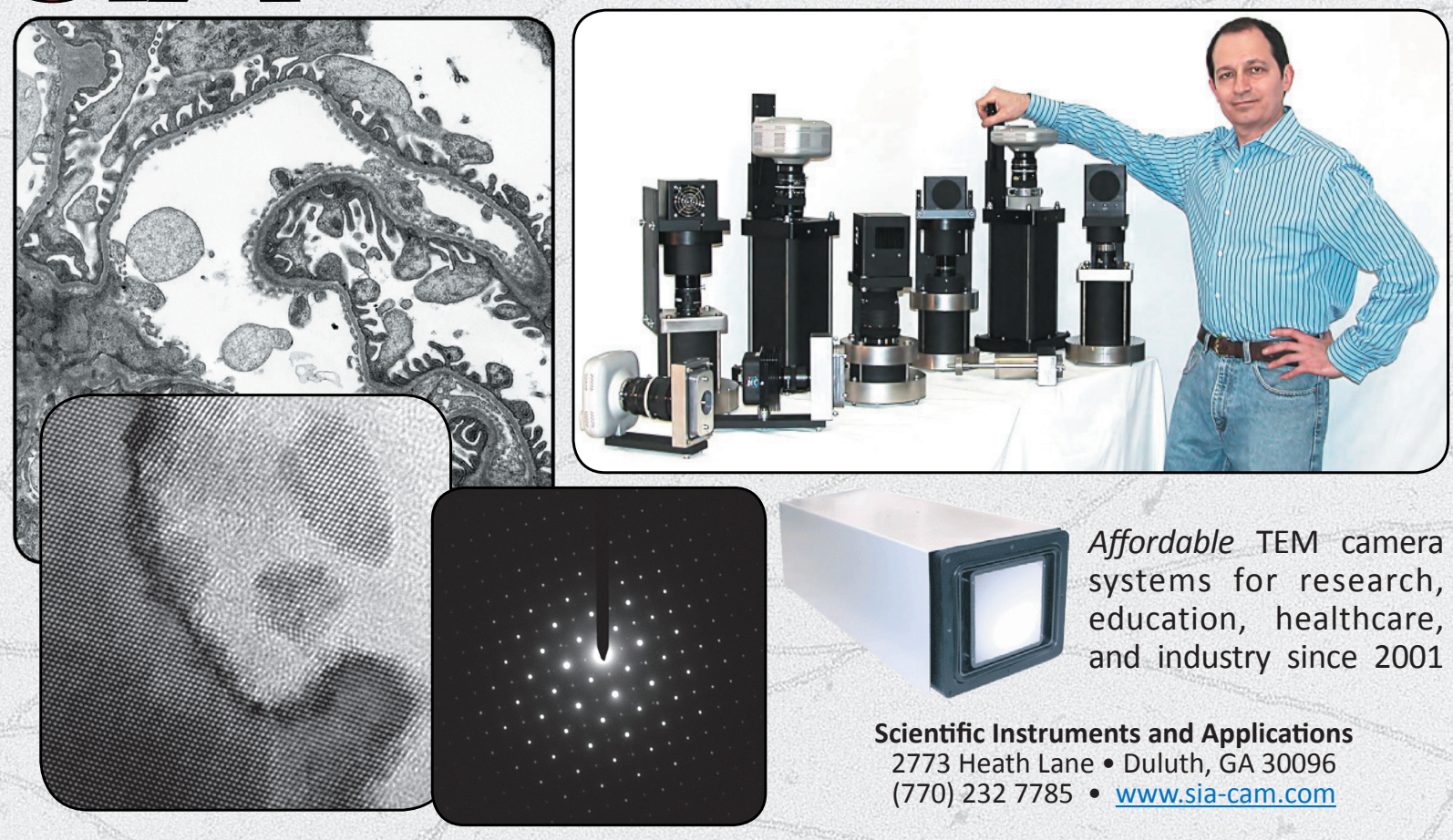

Scientific Instruments and Applications

2773 Heath Lane • Duluth, GA 30096

(770) 2327785 • www.sia-cam.com

\section{CAMBRIDGE}

New to the Advances in Microscopy and Microanalysis book series!

\section{Scanning Electron Microscopy for the Life Sciences}

\section{Heide Schatten}

University of Missouri, Columbia

US\$120.00: Hb: 978-0-521-19599-7: $312 \mathrm{pp}$

Recent developments in scanning electron microscopy (SEM) have resulted in a wealth of new applications for cell and molecular biology, as well as related biological

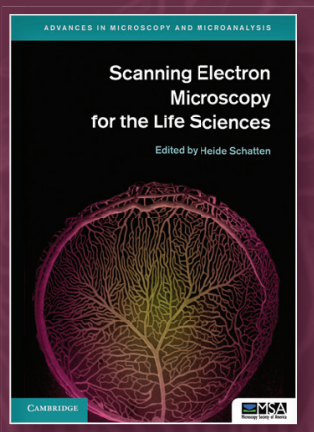

disciplines. It is now possible to analyze macromolecular complexes within their three-dimensional cellular microenvironment in near native states at high resolution, and to identify specific molecu les and their structural and molecular interactions. New approaches include cryo-SEM applications and environmental SEM (ESEM), staining techniques and processing applications combining embedding and resin-extraction for imaging with high resolution SEM, and advances in immuno-labeling. With chapters written by experts, this guide gives an overview of SEM and sample processing for SEM, and highlights several advances in cell and molecular biology that greatly benefited from using conventional, cryo, immuno, and high-resolution SEM.

\section{About the series}

The Press currently publishes the Microscopy and Microanalysis (MAM) journal in conjunction with the MSA, which reaches 4,000 microscopists and is affiliated with 12 international microscopy societies. The series would be a natural development from this journal, and will take a broad view of the discipline, covering topics from instrumentation to imaging, methodology and analysis across physical science, materials science, biology and medicine. Books commissioned for the series will range from advanced undergraduate textbooks through to research and practitioner oriented monographs for researchers. The series aims to produce a coherent source of material, encouraging the communication and exchange of ideas across these divergent fields, ensuring that the series appeals to a broad community in the physical and life sciences.

\section{Forthcoming titles in this series:}

Microscopic Nanocharacterization of Materials by Michael Isaacson

Energy Filtered Electron Microscopy and Electron Spectroscopy by Richard Leapman

Dynamic Transmission Electron Microscopy by Nigel Browning, Thomas LaGrange, Bryan Reed, Henning Stahlberg, Bradley Siwick 


\section{THE NEW DESK V}

\section{THE GOLD STANDARD IN SAMPLE PREPARATION}

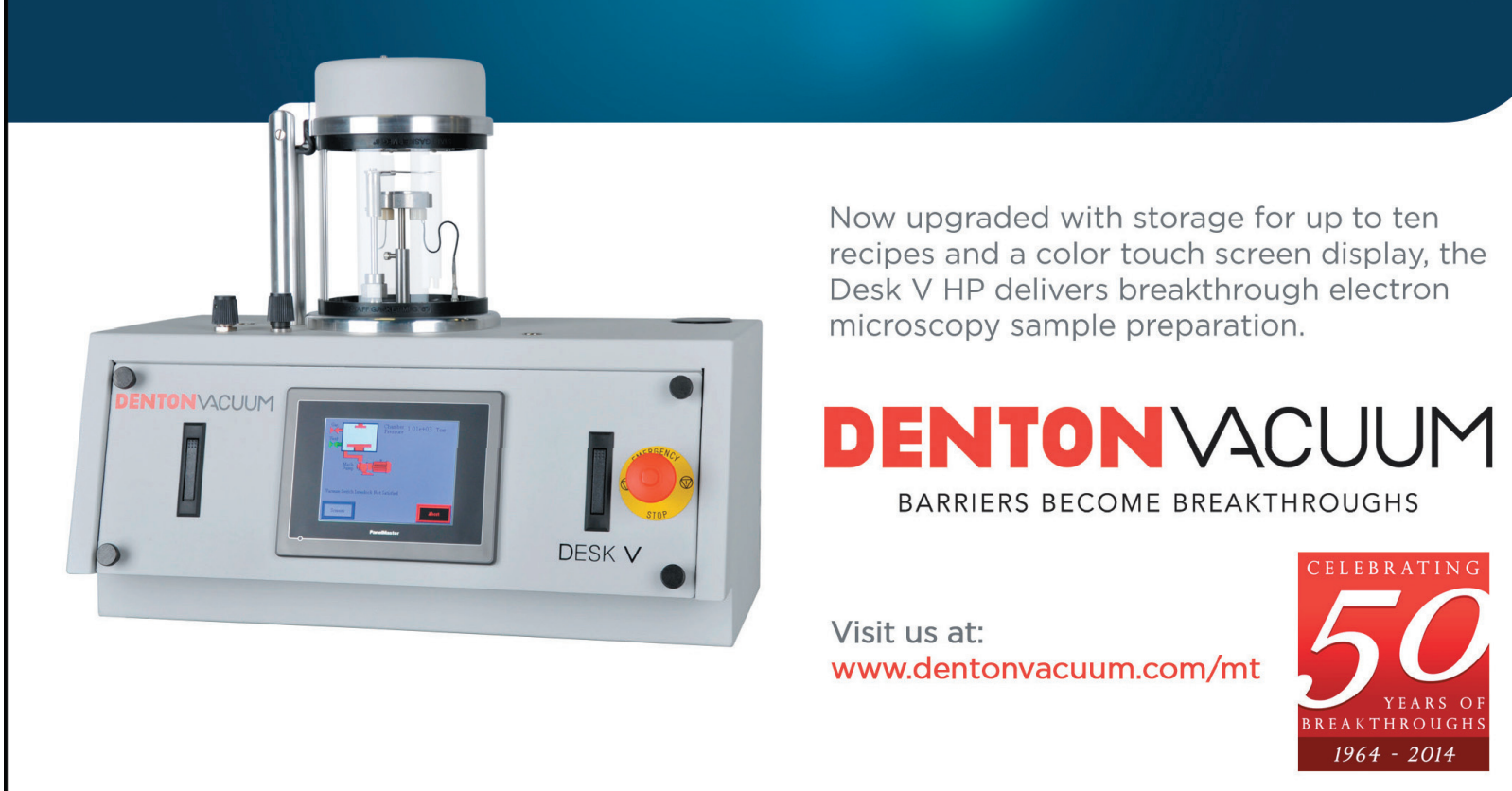

\begin{tabular}{ll}
\hline INDEX TO ADVERTISERS & \\
\hline Advanced Microscopy Techniques, AMT & A5 \\
ASCB & A16 \\
Bruker MicroCT & A3 \\
Bruker Nano GmbH & A21 \\
Carl Zeiss Microscopy, LLC & A11 \\
Denton Vacuum & A24 \\
Diatome & A17 \\
EDAX, Inc. & A12 \\
Electron Microscopy Sciences, EMS & Cover 2 \\
Evans Analytical Group & A19 \\
FEI Company & A14 \\
Gatan & Cover 3 \\
IMC Conference & A22 \\
IUMAS-6 & A18, A20 \\
JEOL USA & Cover 4, A6 \\
MSA Ads & A20, A23 \\
SIA Scientific Applications & A23 \\
SPI Supplies & A10 \\
Ted Pella & A13, A19 \\
Tescan & A15 \\
\hline
\end{tabular}




\section{Heat Up Your In-situ EBSD Work NEW Murano Heating Stage}
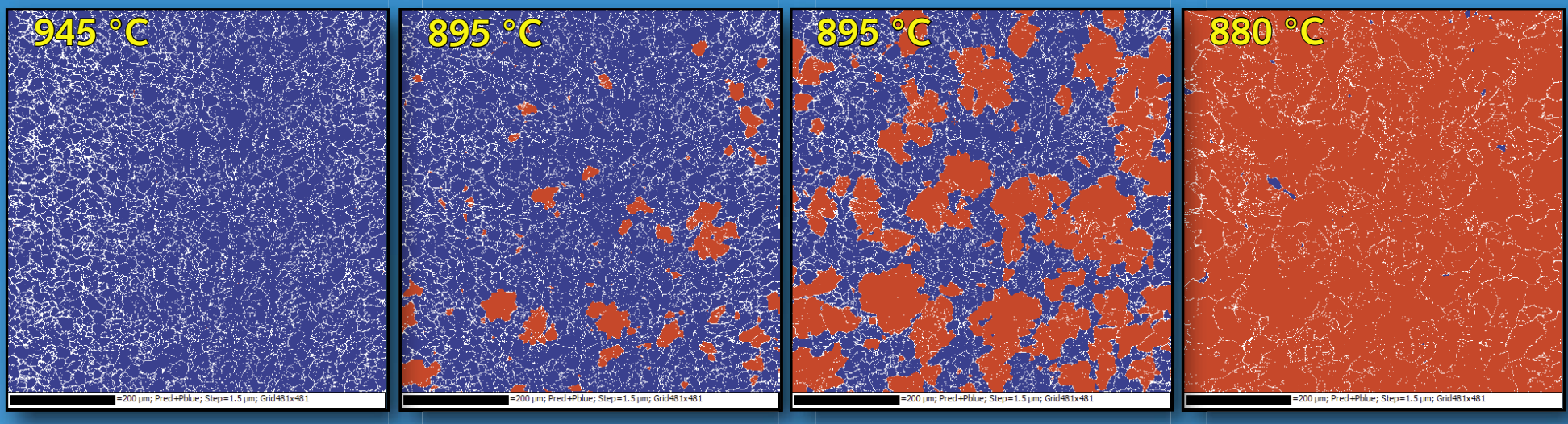

Murano Heating Stage delivers in-situ specimen characterization for your SEM

- Compatible with geometry constraints of EBSD / FIB /SED applications

- Study real time recrystallization and phase transformations from ambient to $950{ }^{\circ} \mathrm{C}$

- Removable platform for multiple specimens storage and mounting

- Optional gas injection to aid catalysis

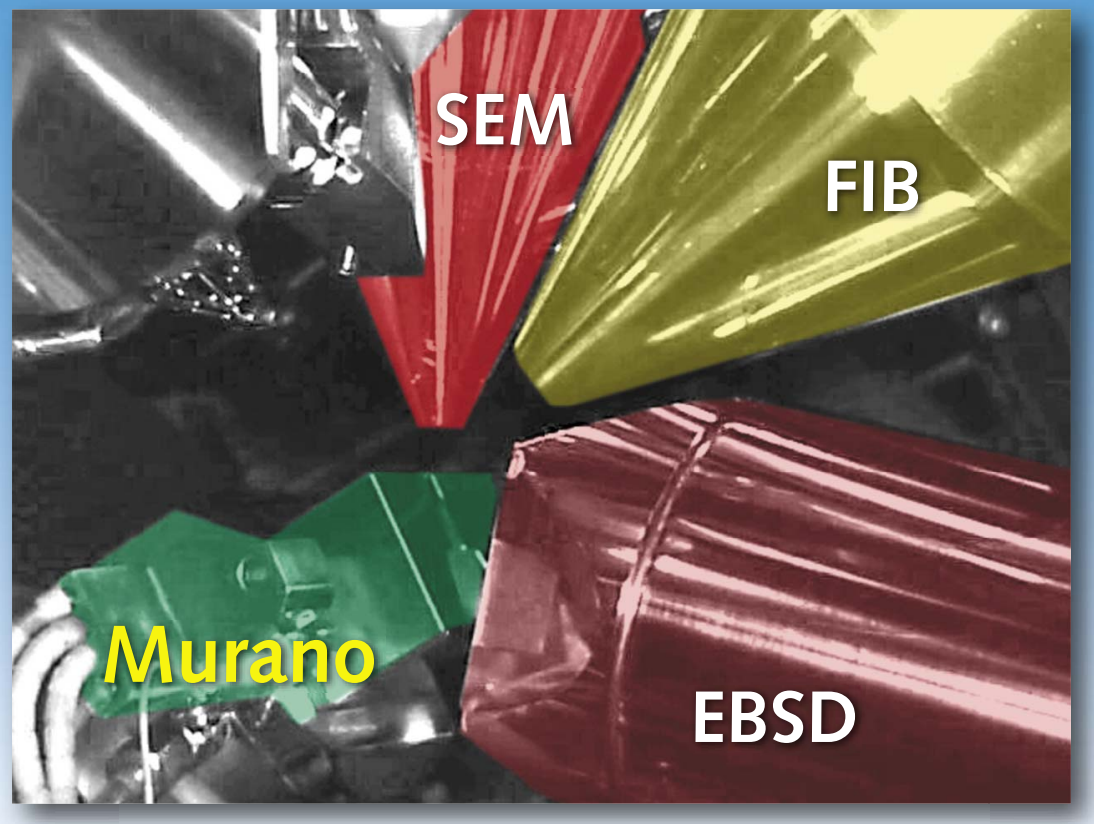

Top Images: EBSD phase maps showing austenite to ferrite transformation from $945^{\circ} \mathrm{C}$ to $880^{\circ} \mathrm{C}$, austenite is blue (dark) and ferrite is red (light). Measurements were taken using a single low carbon steel specimen heated to $945^{\circ} \mathrm{C}$ then cooled at $1{ }^{\circ} \mathrm{C}$ per minute until the start of phase transformation was observed. Once transformation started, temperature was held to observe development of the phase change in individual grains before cooling resumed. Data courtesy of Dr. Singh Ubhi from Oxford Instruments. Bottom Image: SEM chamber view with EBSD, FIB, SED.

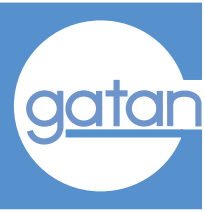

www.gatan.com

\section{Murano Heating Stage $950^{\circ} \mathrm{C}$ In-situ Heating Stage for SEM FIB EBSD}




\section{REACH FOR THE HIGHEST RESOLUTION AT THE ATOMIC SCALE}

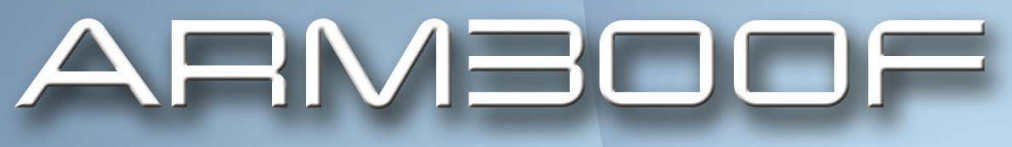

$\ulcorner\longmapsto \risingdotseq \sqsubseteq \boxminus A N \square A \boxminus M$

Proven performance - unmatched raw data.

The highest resolution commercially-available Atomic Resolution TEM in the world.

- 63 picometer point-to-point resolution guaranteed

- 80-300 kV cold FEG

- Large solid angle SDD for atomic level chemistry

- Available with or without Cs correctors for TEM and STEM

- All-JEOL column optics and software

- Ultimate stability

- Renowned service and support
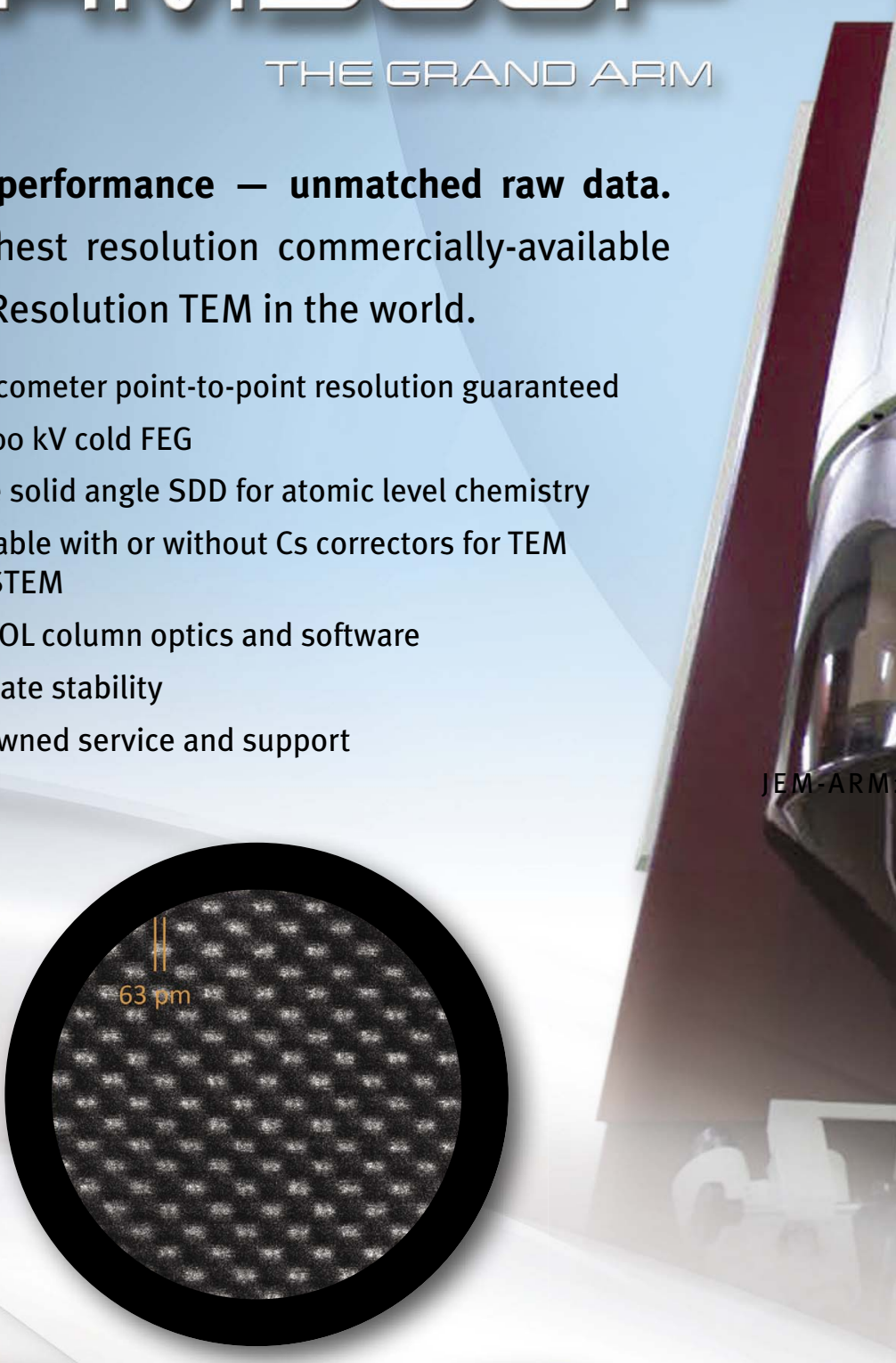

Solutions for Innovation

www.jeolusa.com

salesinfo@jeol.com•978-535-5900
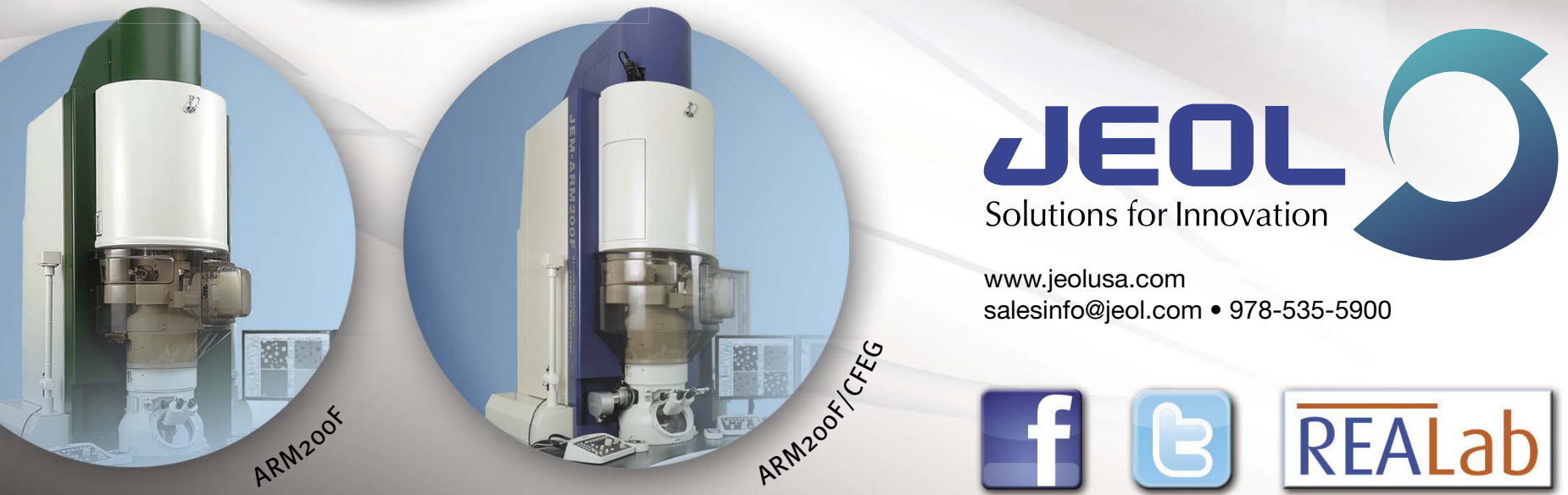